\title{
Training Information Brokers: A Curriculum Model
}

\author{
Dimitar Christozov \\ American University in \\ Bulgaria, Blagoevgrad, \\ Bulgaria
}

dgc@aubg.bg

\author{
Stoyan Denchev, \\ Stefka Toleva - Stoimenova, and \\ Katya Rasheva - Yordanova \\ State University of Library Science \\ and Information Technologies, \\ Sofia, Bulgaria
}

\begin{abstract}
The paper shares experience accumulated in launching and implementing a curriculum model for bachelor level training of professionals - Information Brokers - to serve as mediators and consultants to different kind of clients. This requires that professional possess knowledge and skills in several areas as information technology, mathematics and statistics, business and economics, and consulting skills as well. The way, how to build the corpus of knowledge and skills needed for the profession of Information Brokers, how it is structured and ordered is presented, commented and assessed.
\end{abstract}

Keywords: Information Brokerage, curriculum model, baccalaureate level

\section{Introduction}

Designing and launching an entirely new program, leading to bachelor degree, is a challenging job for every school, especially if this program is a new one not only for the school itself, but globally. Such project requires allocation of significant resources, first of all human and intellectual resources, but also financial, material and informational. The puzzle of the new program is constructed piece by pieces from information collected from many sources. Also designing the curriculum for a new program has to show balance between what are needed and what are available training resources - relevant courses taught in other majors, instructors, training materials, laboratories, equipment, etc. available in the school, but designed for different purpose.

Here we will share the experience we gained in launching a major for "Information Brokerage" in the State University of Library Studies and Information Technologies, Sofia. The program was launched in academic year 2003/04 and the first class graduated in 2006/07.

Material published as part of this publication, either on-line or in print, is copyrighted by the Informing Science Institute. Permission to make digital or paper copy of part or all of these works for personal or classroom use is granted without fee provided that the copies are not made or distributed for profit or commercial advantage AND that copies 1) bear this notice in full and 2) give the full citation on the first page. It is permissible to abstract these works so long as credit is given. To copy in all other cases or to republish or to post on a serveror to redistribute to lists requires specific permission and payment of a fee. Contact Publisher@ InformingScience.org to request redistribution permission.

Information Brokerage, as an educational subject, existed solely as qualifying professionaltraining at that time (Rachmeler, 1995). Special programs were designed for serving different categories of students, e.g. designed to qualify unemployed professionals to find a new carrier path (Christozov \& Nikolova, 2001). Some universities of- 
fered graduate programs oriented to train the expertise we are defining as Information Brokers (http://www.libsci.sc.edu/). But at the time of launching the major, mentioned above, there were no, to the best of our knowledge, programs designed for a bachelor level of Information Brokerage.

At that time, we had clear understanding about how important is the early start of training in the field to accomplish the objectives of this program, as well as quite clear understanding what has to be included in such a program. Also we were fully aware about the difficulties in building such program, because we lacked direct sources we may learn from, and more import antly, we lacked knowledge of social and professional experience students need to advance in this subject. The third difficulty comes from the extensive and diverse corpus of knowledge we had to accumulate to proceed. The lack of prior experience required ordering carefully the sequence of topics to allow smooth grow.

The paper is organized in the following way:

The first section addresses the social, technological and economic factors that create the necessity of launching the program.

In second section we described our preliminary assumptions about the knowledge and skills needed to excel in the profession of information brokers. They have not changed significantly since the launching of the program.

The third section describes the curriculum of the program.

The fourth section comments strengths and weaknesses of the program.

In the Conclusion we list recommendations for further development of the program and assess the level of achievement of the initial objectives.

\section{Needs of Properly Educated Information Mediators}

The dilemma "sinking in information and being not enough informed", characterize the last twenty years. There are two major fact ors in support of the need for establishing proper education in the field of informing clients, and therefore the need for professionally educat ed information mediators - Information Brokers.

The first one is the advancement of information technologies and their impact. In the last years all facets of human life have changed completely, making information technologies unavoidable. The second major fact or is globalization of the world economy, with two basic consequences:

- To do his or her everyday business, to make proper and rational decisions, one needs information - complete, correct, reliable, etc. Both parties, sellers and clients, have similar access to information and to succeed in the business everyone has to be better informed.

- The amount of available information, which flooded our life, makes impossible to dedicate enough attention to comprehend possible effects of different activity paths.

Effectiveness and efficiency in dealing with information becomes the most significant factor for success in any sphere of human activities and at the same time exploring information becomes more complex requiring special knowledge and techniques.

Dedication of significant efforts for development own expertise in the field of information research often conflicts with the other needs of particular profession. The large companies are able to establish their own bodies of professionals providing information services. The understanding of the need for proper use of information is growing and it is extended further to medium and 
even small size businesses. Often, they solved the above-mentioned conflict by using external consultants, whose role is to serve as mediators between "flood of information" and the client Information Brokers. Thus the market demand for services of Information Brokers in its two qualities - as independent consultants, and as information service experts is growing and this process will continue to grow.

\section{The Corpus of Knowledge}

We have recognized the following special areas of expertise, individuals need to posses to be a successful professional Information Broker. Of course, any additional qualification in a particular specific area of knowledge is a bonus.

\section{Information Searching and Delivery}

The following factors affect effective and efficient search of information:

The volume of accessible resources: Through Internet one can get free access to vast volume of information.

Not free accessible sou rces: The most valuable information is delivered via sources, which do not provide free access. Also, the most precious information is available as 'old fashion' hard copy or it is possessed solely by human experts.

Good unde rstanding about the tools used by search engines (e.g. organization of indexes) helps in writing queries, which improves the quality of the retrieved sample.

The diversity of sources, which impacts the quality of information, requires expertise to allow for assessment of reliability and trustfulness of information and expertise for its verification.

\section{Efficient Use of IT}

Skills of efficient use of Information technology are essential nowadays for everybody, but this is especially important for professionals dealing with information.

\section{Analysis and Structuring of Information and Creation of Secondary Information}

Nowadays, information retrieval is not sufficient. Retrieved information need to be analyzed, structured and presented to clients in the best form to serve their needs.

Statistical knowledge, as well as knowledge about data analysis drawn from other disciplines, such as machine learning, artificial intelligence, etc., is essential for discovering the pieces of valuable information from available data. Additionally, presentation of information requires knowledge of psychology, because the role of Information Broker is to serve human clients.

Achieving expertise in this broad area is critical for successful Information Broker, but education for it on the bachelor level is quite challenging:

The students are still inexperienced about the realities in the business, and cannot understand clearly the complexity of the problems;

The lack of sufficient mathematical background, needed to comprehend those methods and techniques, does not allows students to start building the necessary knowledge and skills on the earlier stages of their studies;

The area is too broad, some of the topics and techniques are still on research level, but dynamics in the filed requires introducing them to students. 


\section{Consulting and Business}

The essence of the job of an Information Broker is providing consulting services. Students need to gain information and to develop skills in performing consulting activities in a professional manner, which includes writing offers, contracting, planning, reporting, etc. Skills of running business as basic accounting and principles of management are also quite important. Additionally, majority of problems Information Brokers will face in their professional career are businessrelated. This places underst anding about the business and commerce among the necessary elements of training.

\section{Information Systems Design}

A special part the corpus of knowledge needed is the design of information systems. Their role is to connect clients and technical staff.

\section{The Structure of the Curriculum Model}

In building the curriculum model of Information Brokerage major, we face the problem of how to order courses in a way to allow smooth introduction to so diverse fields. Also, we have to solve the problem of appropriately trained instructors. The curriculum model applied is a tradeoff between, what was recognized as necessary and what was available and possible.

We divided the courses offered in several categories:

\section{Introduction to the Profession}

"Introduction to Information Brokerage" (see Christozov \& Denchev, 2004) is the very first course in the curriculum. Its role is drawing the big picture. It defines the role of Information Brokers in the society, the major problems they deal with: information retrieval from heterogeneous sources, structuring, generalization and presentation of secondary information. The course introduces fundamental concepts as information, communication, system, cybernetic system, information system, information technology, etc.

\section{Fundamental Knowledge}

The first two years of study, curriculum stresses on building the required fundament al knowledge. The basic concepts needed in the different fields of study are presented in this group. The following disciplines contribute in building the corpus of fundamental knowledge:

- Mathematics (Algebra, Analy sis)

- Informatics Fundamentals (Discrete Mathematics)

- Information Systems

- Information Science Fundamentals

- Information society and policy

- Data/documents processing

- Documental sources

- Knowledge organization and management, etc.

\section{Specific Knowledge}

This part represents the backbone of the curriculum. Students are trained on specific qualification needed by Information Brokers. Here we placed the following courses: 
- Information Brokerage,

- Information Management,

- Probability and Statistic,

- Systems analysis,

- Theory and Practice of Consulting,

- Introduction to IB Low and Legal regulation,

- Mathematical Foundations of IB.

A brief survey of the disciplines is proposed below:

Information Management covers the factors necessary for successful management of information systems. Bothtechnical and behavioral aspects of project management are applied within the context of an information systems development process.

Probability and Statistic develops the skills and insights required to make effective use of statistical methods and techniques. The course covers rigorous training on fundamentals of probability theory and applications of basic statistical methods, such as regression analy sis and forecasting. The course also trains the use of statistical soft ware.

System analysis provides experience determining system requirements and developing a logical design. A variety of development approaches are exposed to the students.

Theory and Practice of Consulting trains students on basic skills required from professional consult ants: writing CV, developing offers for tenders, contracting, planning, reporting, etc. Also it trains some basic techniques as market study and reading financial statements.

Mathematical Foundations of Information Brokerage represents an introduction to modern financial theory, mathematical techniques and formal mathematical reasoning; it emphasizes development of practical application skills as well. The students are introduced with securities market, "portfolio" theory, and to the modern banking system.

Low and Legal Regulation. Students are introduced to legal issues of professional practice and ethical behavior. Topics included are drawn from the fields of commerce and contractual law.

Information Broke rage. This is a cap-stone project. It emphasizes the application of specific knowledge acquired so far to fulfill effective information service, consult ing, information management and intermediation. It addresses also the ability of students to integrate the knowledge and skills to solve problems and to run business in the field of information service.

Students may choose also among the following elective courses: E-commerce and E-Business, Artificial Intelligence and Expert Systems, Scientific research methods, which also contribute to this area of expertise.

\section{Technical Skills}

Training technical skills both in using information technologies and in applying specific analytical methods are essential for Information Brokers. This group of courses includes:

- Optimization,

- Applied Software,

- Internet,

- Database Design and Integration,

- Programming Fundamentals,

- Computing system architectures, 
- Computing Networks and communications,

- Information security,

- Software Ergonomics,

- Projects Design and Management.

The students acquire experience to algorithm development, principles and application of computer hardware and soft ware programming, database, computing net works and communicat ions etc. They will use them as tools for organization, communication, research, and problem solving.

The group of elective courses in this category is composed by: Object-Oriented Programming, Logic Programming, Artificial Intelligence and Expert Systems, etc.

The technical disciplines form basis for abstract, technical, and algorithmic way of thinking, "computer literacy" and "information technology literacy". They give the Infobroker the necessary technical skills to collect, summarize, process and interpret dat a and information in design, development and implementation of contemporary information systems.

\section{Social and Business Skills}

The next area covered by the curriculum includes courses oriented to social and business skills of the fut ure brokers.

Besides technical background, each Information Broker is expected to operate effectively and efficiently in the society. This includes accepting and valuing the diverse opinions and perspectives of others, accept ing responsibility for professional and personal behavior and, keeping abreast of social and political developments. The disciplines Philosophy, Political science and Business Psychology are classified in this group.

Since the Information Brokers operate within organizations and with organizational systems, they must also understand organizations and functions within organizations (finance, marketing, human resources and so on). In the curriculum there are courses, like Company Management, Business communications, International Finance, Competition. They contribute in acquiring of useful business skills and substantive managerial abilities of students.

\section{Language Skills}

The last, but not the least important group of subjects is related to training language skills. Currently about $90 \%$ of the content accessible on Internet is in English, which makes proficiency in English the necessary skill. English is studied during every year of the curriculum and includes four levels: Elementary, Pre-Intermediate, Intermediate u Upper-Intermediate. Starting this year an additional intensive English course is offered for graduating seniors, which includes four classes twice a week. This guarantees working knowledge of English for all graduates.

The Business Russian is an optional language course in the IB curriculum. It requires some preliminary knowledge of Russian on intermediate level.

\section{Discussion after Four Years of Experience}

As a field of academic study, Information Brokerage is new not only for our school. There are several forms of post-graduate qualification training, especially addressing training of unemployed professionals. This attempt of offering Information Brokering as a regular discipline meets current demand. The growing interest for this new field is an indication for the recognized conscious need for such professionals. Evidence of this tendency is the increasing number of applicants for study Information Brokerage over the years (see Table 1). The word tendency of switching from more technical to more analytical areas affects the job market in Bulgaria as well. In the 
same time, the job market has no experience with such profession and the role of the first graduates is to create this market.

Table 1: Number of applicants by academic year

\begin{tabular}{|c|c|}
\hline ACADEMIC YEAR & NUMBER OF CANDIDATES $^{*}$ \\
\hline $2003 / 2004$ & 539 \\
\hline $2004 / 2005$ & 764 \\
\hline $2005 / 2006$ & 1314 \\
\hline $2006 / 2007$ & 2593 \\
\hline
\end{tabular}

Combined number of candidates for IT and IB majors.

The Information Brokerage curriculum in place today is the product of four years of experimentation and refinement. A matter of some difficulties in this long process was lack of skilled instructors, training resources, textbooks and the last but not least lack of prior experience to draw from.

\section{Conclusion}

Two nat ural questions need to be answered:

To what extent the implemented curriculum meets the initially recognized objectives in launching the Information Brokerage program?

Whether the graduates will succeed in their careers in the business?

The answer to the first question is positive. Graduating students have potential to offer quality information service. Only time can answer the second one.

\section{References}

Christozov, D., \& Nikolova, I. (2001). Infobroker - An emerging profession of in forming meditors? Proceedings Informing Science Conference, Krakow 2001.

Christozov, D., \& Denchev, S. (2004) Information brokerage: Lecture notes, WINI-1837, Sofia (in Bugarian).

Rachmeler, S. (Ed.). (1995). Start your own information broker service. Prentice Hall.

\section{Biographies}

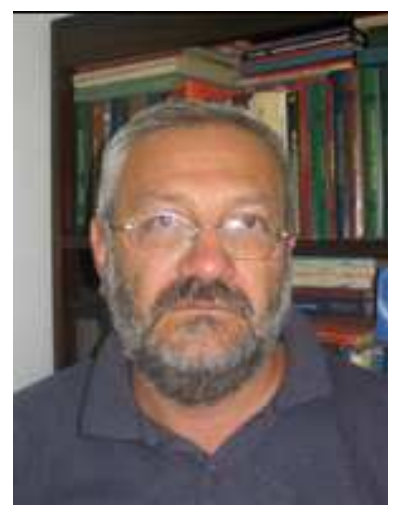

Dimitar Christozov is a Professor of Computer Science at the American University in Bulgaria, Blagoevgrad 2700, Bulgaria since 1993. He has more than 25 years of experience in areas as computer science, quality management and information systems. He graduated Mathematics from Sofia University "St. Kliment Ohridski" in 1979. He completed his $\mathrm{PhD}$ thesis "Computer Aided Evaluation of Machine Reliability" in 1986. In ICTT "Informa" (1986-1993) Dr. Christozov was involved in establishing the national information net work for technology transfer and research in the areas of technologies assessment, integral quality measures and information systems for quality management. In these areas he was recognized as one of the leading experts in Bulgaria. Professor Christozov has more than 50 publications as sepa- 
rate volume, journal papers and papers in refereed proceedings. He is a founding member of Informing Science Institute and chair of Bulgarian Informing Science Society; and member of the Bulgarian Statistical Society.

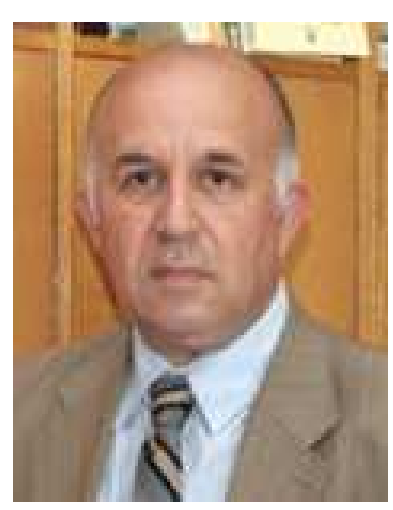

Stoyan Denchev, a Professor of Economics, is a Rector of State University of Library Studies and Information Technologies, Sofia. He graduated at Sofia University "St. Kliment Ohridski” in 1978, MS, Public Administration and Computer Science. From 1978 to 1986 he worked at the Central Machine-building Instit ute. In ICTT "Informa"(1986 to 1988) he filled the positions of Direct or of Science and then Vice Director-General. He obtained his PhD in Computers and Information Systems in 1983 and his Doctor of Economics degree in 2004. In 2005 he was elected as a Professor. In 1988/9 he was a Visiting Professor at University of California, Berkeley. His research fields are: System Analysis, Computer Sciences, Information Technologies, Information Systems, Information Security, Public Administration and Human Resource Management. He has more than 150 publications. From 2006 he is a chairman of the Union of Bulgarian Libraries.

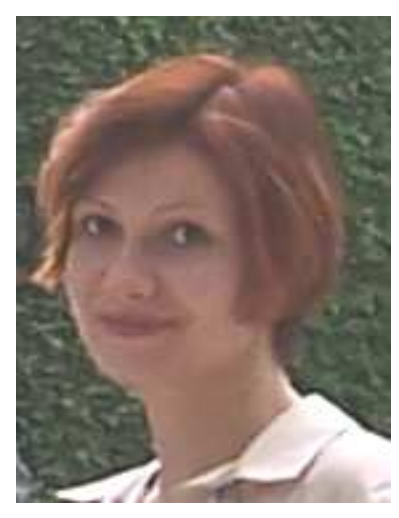

Stefk a Tole va-Stoimenova is a Senior Assist ant Professor of Mathematics and Informatics at the State University of Library Studies and Information Technologies, Sofia, Tzarigradsko shosse Blvd. 119, Bulgaria 1784, s_toleva@yahoo.com. She has obtained her MSc degree in Industrial Aut omation from the Faculty of Automation and System Design, Technical University - Sofia. Her main research interests are in the field of Automation and Informatics. She is currently researching to obtain his PhD degree on Informing Science and Automated Information Systems. She is a member of Bulgarian Informing Science Society.

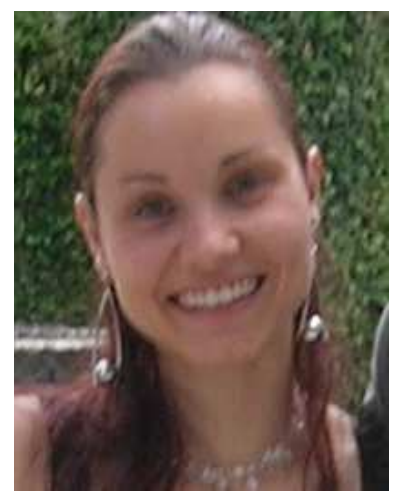

Katya Rashe va-Yordanova is an Assistant Professor of Computer Science at the State University of Library Studies and Information Technologies, Sofia, Tzarigradsko shosse Blvd. 119, Bulgaria 1784, katia_rasheva@gbg.bg. She has an MSc degree in Informationtechnologies and a second MSc in Business and Administrative communications from the SULSIT, Sofia. Her research interests are in the field of Computer Science, Information Technology, and Information Security. She is a member of Bulgarian Informing Science Society. 